\title{
DETERMINATION OF THE OPTIMAL CONDITIONS FOR THE ADSORPTION OF CADMIUM IONS AND PHENOL ON CHESTNUT (CASTANEA SATIVA) SHELL
}

\author{
G. VÁZQUEZ \\ J. GONZÁLEZ-ÁLVAREZ* \\ M.S. FREIRE \\ M. CALVO \\ G. ANTORRENA
}

Received: 10/09/08

Accepted: 30/10/08

\author{
Department of Chemical Engineering \\ University of Santiago de Compostela \\ School of Engineering \\ Rua Lope Gómez de Marzoa, s/n \\ 15782 Santiago de Compostela, Spain
}

\section{ABSTRACT}

Adsorption of cadmium ions and phenol from aqueous solutions on chestnut (Castanea sativa) shell was studied. An incomplete $3^{3}$ factorial design was applied to investigate the influence of the initial cadmium ions (20-60-100 mg l-1) or phenol concentration (0.01-0.255$\left.0.5 \mathrm{~g} \mathrm{l}^{-1}\right)$, temperature $\left(10-25-40^{\circ} \mathrm{C}\right.$ for cadmium and $10-35-60^{\circ} \mathrm{C}$ for phenol) and $\mathrm{pH}$ (5.5-7.08.5 for $\mathrm{Cd}^{2+}$ ions and 2.5-6.0-9.5 for phenol) on the amount of contaminant adsorbed and on the adsorption percentage. Statistical analysis of the results showed the significance of the individual factors and their interactions on both adsorption processes. The best conditions for high cadmium ions and phenol removal within the experimental ranges of the variables studied were the natural $\mathrm{pH}$ (around 5.5) and a temperature of $25^{\circ} \mathrm{C}$ for cadmium ions and $60^{\circ} \mathrm{C}$ for phenol. Under these conditions, adsorption equilibrium was modelled by the Freundlich isotherm for cadmium ions and by the Langmuir isotherm for phenol.

KEYWORDS: removal, cadmium ions, phenol, chestnut shell, experimental statistical design.

\section{INTRODUCTION}

Industrial activities and technological development generate effluents containing heavy metals and other hazardous species, whose concentration must be reduced to meet legislative standards. Thus, cadmium and phenol are generally considered to be highly toxic and can provoke risks to human health.

The selection of a particular treatment procedure depends on the nature of the effluent, waste type and concentration, presence of other constituents, level of removal required and economics (Ghodbane et al., 2008). Adsorption has gained importance over other techniques such as precipitation, ion exchange, filtration or solvent extraction due to its good performance for removing contaminants from industrial effluents. On the other hand, there has been a constant search for new adsorbents among industrial and agricultural residues with high adsorption capacity and selectivity, abundant in nature and cheap (Bailey et al., 1999; Ho and McKay, 1999; Fiset et al., 2000; Calace et al., 2002; Rao and Viraraghavan, 2002).

Chestnut shell from the Castanea sativa species is generated as a waste during the peeling of chestnut to produce food derivatives and it is used as fuel. In a previous work (Vázquez et al., 2008), a chemical composition analysis indicated that the shell contains lignin (32.0\% o.d. shell), cellulose $(19.2 \%$ o.d. shell) and other compounds with functional groups that could interact with $\mathrm{Cd}^{2+}$ and phenol (Garg et al., 2008a; Rao and Viraraghavan, 2002). Although adsorption studies with other similar lignocellulosic materials such as nut, coconut and walnut shells have been performed (Bailey et al., 1999; Ho and McKay, 1999), no information has been found in literature on the utilization of chestnut shell as adsorbent. 
Published adsorption studies have demonstrated the influence of various parameters: initial concentration, $\mathrm{pH}$, temperature, solid/liquid ratio, particle size and mass of adsorbent, on the removal efficiency of different species. However, the interaction among variables has been scarcely considered. In this respect, a statistical experimental design can be employed to determine the effects of operational variables and their interactions and to optimise the adsorption process, avoiding the traditional one-factor-at-a-time experiments (Carmona et al., 2005; Huang et al., 2008).

In this work, the use of chestnut shell as a low-cost adsorbent for the removal of cadmium ions and phenol from aqueous solutions is presented. In order to optimize the adsorption process, an incomplete $3^{3}$ factorial design was applied to investigate the individual and interactive effects of the initial concentration, temperature and $\mathrm{pH}$ on the shell capacity for removing both contaminants and on the adsorption percentage. In addition, the equilibrium isotherms (Freundlich and Langmuir models) were determined using the conditions selected from the statistical design of experiments.

\section{MATERIALS AND METHODS}

\subsection{Adsorbent preparation}

Chestnut shell supplied by a food factory (Marrón Glacé, S.L., Ourense, NW of Spain) was air-dried till equilibrium moisture content (approximately, 18\% w/w), ground in a hammer mill and after classified, the fraction with particle sizes between 0.1 and $2 \mathrm{~mm}$ was selected. In order to polymerise and immobilise the water-soluble phenolic compounds, the shell was treated with formaldehyde in acid medium according to Vázquez et al. (1994): a 1/4 (v/v) mixture of $37 \%$ formaldehyde and $0.2 \mathrm{~N}$ sulphuric acid was heated to $50^{\circ} \mathrm{C}$, chestnut shell was added in a $2 / 5$ ( $\mathrm{g}$ of shell $\mathrm{ml}^{-1}$ of formaldehyde) ratio and, after stirring at $50^{\circ} \mathrm{C}$ for $2 \mathrm{~h}$, the suspension was filtered through a Büchner funnel. The shell was washed with distilled water until the washing $\mathrm{pH}$ was approximately 4 and air-dried.

The natural $\mathrm{pH}$ of the shell (around 4.5) was determined by stirring $1 \mathrm{~g}$ of chestnut shell in $100 \mathrm{ml}$ of distilled water for $24 \mathrm{~h}$.

\subsection{Statistical design of experiments}

To study the influence of initial adsorbate concentration $\left(X_{1}, 20-60-100 \mathrm{mg} \mathrm{I}^{-1}\right.$ for cadmium ions and 0.01-0.255-0.5 $\mathrm{g} \mathrm{I}^{-1}$ for phenol), temperature $\left(X_{2}, 10-25-40^{\circ} \mathrm{C}\right.$ for cadmium ions and $10-35-60^{\circ} \mathrm{C}$ for phenol) and $\mathrm{pH}\left(\mathrm{X}_{3}, 5.5-7.0-8.5\right.$ for $\mathrm{Cd}^{2+}$ and 2.5-6.0-9.5 for phenol) on the amount of adsorbed contaminant $\left(\mathrm{Y}_{1}, \mathrm{mg}\right.$ adsorbed/g of chestnut shell) and on the adsorption percentage $\left(\mathrm{Y}_{2}, \%\right)$, an incomplete $3^{3}$ factorial design (Box-Behnken model) was employed (Table 1). Twelve experiments were required and all of them were done in duplicate. The following variables were kept constant: solid/liquid ratio, $1 / 100\left(\mathrm{~g} \mathrm{ml}^{-1}\right)$ for cadmium ions and $1 / 50\left(\mathrm{~g} \mathrm{ml}^{-1}\right)$ for phenol; contact time, 4 days for cadmium ions and 8 days for phenol (the optimum contact time determined in previous experiments for attaining adsorption equilibrium), and particle size between 0.1 and $2 \mathrm{~mm}$.

Multiple regression analysis using SPSS 13.0 software was employed to fit the experimental data with polynomials of the form of Equation 1:

$$
Y_{j}=a_{0 j}+a_{1 j} X_{1}^{*}+a_{2 j} X_{2}^{*}+a_{3 j} X_{3}^{*}+a_{12 j} X_{1}^{*} X_{2}^{*}+a_{13 j} X_{1}^{*} X_{3}^{*}+a_{23 j} X_{2}^{*} X_{3}^{*}+a_{11 j} X_{1}^{* 2}+a_{22 j} X_{2}^{* 2}+a_{33 j} X_{3}^{* 2}
$$

where $Y_{j}$ is the predicted response, $X_{i}^{*}$ is the coded value of the independent variable: -1 (low level), 0 (central point) and 1 (high level), $a_{0 j}$ is a constant, $a_{i j}$ is the ith linear coefficient, $a_{i k j}(i \neq k)$ is the linear-by-linear interaction between the input variables and $a_{i j}$ is the quadratic coefficient.

All main factors and interactions that presented a probability value lower than 0.1 were considered statistically significant. The validity of the equations obtained was verified by application of the $F$ test, analysing the correlation coefficients $\left(R^{2}\right.$ and adjusted $\left.R^{2}\right)$ and by comparison between the calculated and experimental values of the $Y_{j}$. 
Table 1. $3^{3}$ incomplete factorial design and experimental results for the dependent variables

\begin{tabular}{|c|c|c|c|c|c|c|c|}
\hline & \multicolumn{3}{|c|}{ Independent variables } & \multicolumn{4}{|c|}{ Dependent variables } \\
\hline Exp. & $\mathrm{X}_{1}{ }^{*}$ & $x_{2}{ }^{*}$ & $\mathrm{X}_{3}{ }^{*}$ & $\begin{array}{c}Y_{1, \mathrm{Cd}} \\
\left(\mathrm{mg} \mathrm{g}^{-1}\right)\end{array}$ & $\begin{array}{l}Y_{1, \text { phenol }} \\
\left(\mathrm{mg} \mathrm{g}^{-1}\right) \\
\end{array}$ & $\begin{array}{l}Y_{2, C d} \\
(\%)\end{array}$ & $\begin{array}{c}Y_{2, \text { phenol }} \\
(\%)\end{array}$ \\
\hline 1.1 & -1 & -1 & $\overline{0}$ & 1.32 & 0.39 & 71.18 & 77.83 \\
\hline 1.2 & -1 & -1 & 0 & 1.33 & 0.39 & 71.08 & 76.34 \\
\hline 2.1 & 1 & -1 & 0 & 3.72 & 4.12 & 34.67 & 17.49 \\
\hline 2.2 & 1 & -1 & 0 & 3.91 & 5.36 & 36.44 & 21.62 \\
\hline 3.1 & -1 & 1 & 0 & 1.32 & 0.50 & 70.91 & 99.41 \\
\hline 3.2 & -1 & 1 & 0 & 1.41 & 0.50 & 75.81 & 99.37 \\
\hline 4.1 & 1 & 1 & 0 & 4.38 & 20.66 & 40.68 & 83.29 \\
\hline 4.2 & 1 & 1 & 0 & 4.31 & 21.87 & 39.98 & 88.17 \\
\hline 5.1 & -1 & 0 & -1 & 1.36 & 0.50 & 73.06 & 98.27 \\
\hline 5.2 & -1 & 0 & -1 & 1.35 & 0.50 & 72.58 & 98.09 \\
\hline 6.1 & 1 & 0 & -1 & 3.86 & 16.40 & 35.97 & 66.14 \\
\hline 6.2 & 1 & 0 & -1 & 4.45 & 16.36 & 41.47 & 65.96 \\
\hline 7.1 & -1 & 0 & 1 & 1.33 & 0.50 & 71.67 & 99.10 \\
\hline 7.2 & -1 & 0 & 1 & 1.34 & 0.48 & 72.04 & 95.35 \\
\hline 8.1 & 1 & 0 & 1 & 4.75 & 12.04 & 44.27 & 48.56 \\
\hline 8.2 & 1 & 0 & 1 & 4.31 & 11.17 & 40.12 & 45.04 \\
\hline 9.1 & 0 & -1 & -1 & 2.70 & 7.49 & 41.62 & 59.20 \\
\hline 9.2 & 0 & -1 & -1 & 2.70 & 6.95 & 41.46 & 54.94 \\
\hline 10.1 & 0 & 1 & -1 & 3.32 & 12.64 & 51.00 & 99.92 \\
\hline 10.2 & 0 & 1 & -1 & 3.45 & 12.64 & 52.85 & 99.93 \\
\hline 11.1 & 0 & -1 & 1 & 2.94 & 5.16 & 45.23 & 40.76 \\
\hline 11.2 & 0 & -1 & 1 & 3.16 & 5.10 & 48.54 & 40.29 \\
\hline 12.1 & 0 & 1 & 1 & 3.26 & 12.63 & 49.92 & 99.80 \\
\hline 12.2 & 0 & 1 & 1 & 3.17 & 12.64 & 48.77 & 99.93 \\
\hline \multirow{2}{*}{\multicolumn{2}{|c|}{ Independent variables }} & \multicolumn{6}{|c|}{ Factor levels } \\
\hline & & \multicolumn{3}{|c|}{ Cadmium ions } & \multicolumn{3}{|c|}{ Phenol } \\
\hline \multirow{2}{*}{$\mathrm{X}_{1}$} & \multirow{2}{*}{$\begin{array}{c}\text { Initial } \\
\text { concentration }\end{array}$} & \multicolumn{3}{|c|}{$\mathrm{mg} \mathrm{l}^{-1}$} & \multicolumn{3}{|c|}{$\mathrm{g} \mathrm{I}^{-1}$} \\
\hline & & 20 & 60 & 100 & 0.01 & 0.255 & 0.500 \\
\hline $\mathrm{X}_{2}$ & $\begin{array}{c}\text { Temperature } \\
\left({ }^{\circ} \mathrm{C}\right)\end{array}$ & 10 & 25 & 40 & 10 & 35 & 60 \\
\hline$X_{3}$ & Initial pH & 5.5 & 7.0 & 8.5 & 2.5 & 6.0 & 9.5 \\
\hline
\end{tabular}

\subsection{Adsorption experiments}

Cadmium and phenol solutions were prepared with reagent grade $\mathrm{Cd}\left(\mathrm{NO}_{3}\right)_{2} \cdot 3 \quad \mathrm{H}_{2} \mathrm{O}$ and phenol (Scharlau Chemie, Barcelona, Spain), respectively.

For both contaminants, batch adsorption experiments were conducted in a series of Erlenmeyer flasks covered with Parafilm ${ }^{\circledR}$ to prevent contamination. Solutions of known concentration and $\mathrm{pH}$ were put in contact with $1 \mathrm{~g}$ of pre-treated chestnut shell, and placed in a water bath shaker maintained at $90 \mathrm{rpm}$ at the desired temperature. When the adsorption process was completed, the solutions were filtered using glass microfibre filter paper and analyzed for remaining cadmium or phenol concentrations by atomic absorption spectrometry (GBC 932 AA atomic absorption spectrometer, Australia) and gas chromatography (HP 5890 Series II Gas chromatograph, USA) (Vázquez et al., 2007), respectively. All measurements were done in triplicate and the results averaged. In addition, equilibrium experiments under the optimal conditions of $\mathrm{pH}$ and temperature were performed for cadmium ions and phenol at various initial concentrations.

The $\mathrm{pH}$ adjustments of the solutions were made with $0.1 \mathrm{M} \mathrm{H}_{2} \mathrm{SO}_{4}$ or $0.1 \mathrm{M} \mathrm{NaOH}$ using a MP230 pHmeter (Mettler-Toledo, Switzerland) to perform the measurements. 


\section{RESULTS AND DISCUSSION}

Phenol and cadmium removal by chestnut shell in batch mode could be dependent on several variables. In previous experiments, it was found that initial concentration, $\mathrm{pH}$ and temperature influenced the adsorption percentage and capacity of the shell for both adsorbates. Therefore, in this work these three variables have been selected to optimize the adsorption process using the statistical design of experiments mentioned earlier.

Table 1 shows for both cadmium ions and phenol adsorption processes the experimental results obtained for the dependent variables studied. In general, the amount of phenol adsorbed by chestnut shell was higher than the amount of cadmium ions adsorbed, being the maximum amount of $\mathrm{Cd}^{2+}$ and phenol taken up by chestnut shell 4.75 and $21.87 \mathrm{mg} \mathrm{g}^{-1}$ of shell, respectively.

The coefficients of the models (Equation 1) were determined and those found to be significant together with the different statistical parameters employed (i.e. the coefficient standard deviation (SD) and significance and the model correlating parameters $\left(R^{2}\right.$ and adjusted $\left.R^{2}\right)$, standard deviation and significance) are presented in Table 2. High correlation coefficients were obtained for all the dependent variables and Figure 1 shows, as an example, a good fit between the calculated and the experimental results for the sorption capacity of chestnut shell for the removal of $\mathrm{Cd}^{2+}$.

By analyzing the results in Table 2, it could be inferred that the most significant main factor on both cadmium and phenol uptake $\left(Y_{1}\right)$ was initial concentration followed by temperature. In principle, the positive values of the temperature and initial concentration coefficients meant that the removal of both contaminants were favoured the higher the temperature and the initial concentration. It is known that the removal capacity of an adsorbent usually increases with increasing initial concentration until its saturation, as the adsorbent offers a limited number of surface binding sites (Aksu, 2001; Dursun et al., 2005). On the other hand, temperature modifies the equilibrium capacity of the adsorbent for a particular sorbate and, increasing temperature increases the diffusion rate of the sorbate within the pores as a result of decreasing solution viscosity (Ghodbane et al., 2008).

It was found that some interactions of factors were also significant at the $10 \%$ of probability level: $\mathrm{pH} \cdot \mathrm{pH}$ for the amount of cadmium adsorbed, $\mathrm{C}_{0} \cdot \mathrm{C}_{0}$ for cadmium adsorption percentage, $\mathrm{C}_{0} \cdot \mathrm{C}_{0}$ and $\mathrm{C}_{0} \cdot \mathrm{T}$ for the amount of phenol adsorbed and $\mathrm{C}_{0} \cdot \mathrm{T}$ and $\mathrm{C}_{0} \cdot \mathrm{pH}$ for phenol adsorption percentage. This information on synergistic and antagonistic effects would not be detected in the univariate optimization of the system.

As an example, Figures 2 and 3 show to the response surfaces and the corresponding contour diagrams for cadmium ions and phenol capacity of chestnut shell, as a function of initial concentration and temperature, for the lowest and the highest $\mathrm{pH}$. For both adsorbates the increase in initial concentration and temperature and the decrease in $\mathrm{pH}$ led to an increase of the sorption capacity of shell. On the other hand, at low $\mathrm{pH}$, higher percentages of adsorption were obtained at low initial concentration and high temperature. The results on the influence of $\mathrm{pH}$ agreed with those reported by other researchers who found that the optimum $\mathrm{pH}$ was 6.0 for cadmium adsorption on olive cake (Al-Anber and Matouq, 2008) and rice husk (Krishnani et al., 2008).

It has been found in literature that the sorption capacity of the sorbent could increase with increasing the temperature of the cadmium solution (Ghodbane et al., 2008; Meena et al., 2008). However, as can be observed in Figure 2, for a fixed initial cadmium concentration, the influence of temperature on the adsorption capacity of chestnut shell is only slightly significant for temperatures higher than $25^{\circ} \mathrm{C}$.

As mentioned above, the increase in both initial phenol concentration and temperature led to an increase of sorption capacity until saturation of chestnut shell (Figure 3). However, at low initial concentration temperature was of little significance. Below a certain temperature level, an increase in adsorption capacity with increasing initial phenol concentration was followed by a slight decrease. With respect to adsorption percentage, for all the $\mathrm{pH}$ values essayed, low initial concentration and high temperature increased the \% of phenol adsorbed on the shell, the highest value being also obtained for the lowest $\mathrm{pH}$. At $\mathrm{pH}$ values lower that the $\mathrm{pK}_{\mathrm{a}}$ value 
(9.99), the degree of ionization of phenol decreases (Goud et al., 2005) and thus its capacity to be adsorbed by chestnut shell increases.

Table 2. Coefficients of the models (Eq. 1) and the statistical parameters establishing their validity

\begin{tabular}{|c|c|c|c|c|c|c|}
\hline \multicolumn{7}{|c|}{ Cadmium ions } \\
\hline & \multicolumn{3}{|c|}{$Y_{1}$} & \multicolumn{3}{|c|}{$Y_{2}$} \\
\hline & Coef. & SD & Sig. & Coef. & SD & Sig. \\
\hline$a_{0}$ & 2.470 & 0.113 & 0.000 & 47.423 & 0.756 & 0.000 \\
\hline$a_{1 j}$ & 1.432 & 0.046 & 0.000 & -16.545 & 0.534 & 0.000 \\
\hline$a_{2 j}$ & 0.177 & 0.046 & 0.001 & 2.481 & 0.534 & 0.000 \\
\hline$a_{12 j}$ & 0.120 & 0.065 & 0.082 & - & & - \\
\hline$a_{23 j}$ & -0.129 & 0.065 & 0.064 & -1.981 & 0.756 & 0.017 \\
\hline$a_{11 j}$ & - & - & - & 8.323 & 0.926 & 0.000 \\
\hline$a_{22 j}$ & 0.242 & 0.092 & 0.018 & - & & - \\
\hline$a_{33 j}$ & 0.374 & 0.092 & 0.001 & - & & - \\
\hline $\mathrm{R}^{2}$ & \multicolumn{3}{|c|}{0.983} & \multicolumn{3}{|c|}{0.983} \\
\hline $\operatorname{Adj} . R^{2}$ & \multirow{2}{*}{\multicolumn{3}{|c|}{$\begin{array}{l}0.977 \\
0.184\end{array}$}} & \multicolumn{3}{|c|}{0.979} \\
\hline SD & & & & \multirow{2}{*}{\multicolumn{3}{|c|}{$\begin{array}{l}2.138 \\
0.000\end{array}$}} \\
\hline Sig. & \multicolumn{3}{|c|}{0.000} & & & \\
\hline \multicolumn{7}{|c|}{ Phenol } \\
\hline & \multicolumn{3}{|c|}{$Y_{1}$} & \multicolumn{3}{|c|}{$Y_{2}$} \\
\hline & Coefficient & SD & Sig. & Coefficient & SD & Sig. \\
\hline$a_{0}$ & 9.405 & 0.290 & 0.000 & 73.157 & 1.779 & 0.000 \\
\hline$a_{1 j}$ & 6.514 & 0.205 & 0.000 & -19.219 & 0.726 & 0.000 \\
\hline$a_{2 j}$ & 3.695 & 0.205 & 0.000 & 23.835 & 0.726 & 0.000 \\
\hline$a_{3 j}$ & -0.860 & 0.205 & 0.001 & -4.601 & 0.726 & 0.000 \\
\hline$a_{12 j}$ & 4.102 & 0.290 & 0.000 & 10.968 & 1.027 & 0.000 \\
\hline$a_{13 j}$ & -1.192 & 0.290 & 0.001 & -4.572 & 1.027 & 0.000 \\
\hline$a_{23 j}$ & - & & - & 4.123 & 1.027 & 0.001 \\
\hline$a_{11 j}$ & -2.421 & 0.290 & 0.000 & - & & - \\
\hline$a_{22 j}$ & - & & - & -2.717 & 1.452 & 0.081 \\
\hline$a_{33 j}$ & - & & - & 3.904 & 1.452 & 0.017 \\
\hline $\mathrm{R}^{2}$ & \multicolumn{3}{|c|}{0.990} & \multicolumn{3}{|c|}{0.993} \\
\hline Adj. $R^{2}$ & \multicolumn{3}{|c|}{0.986} & \multicolumn{3}{|c|}{0.989} \\
\hline SD & \multicolumn{3}{|c|}{0.819} & \multirow{2}{*}{\multicolumn{3}{|c|}{$\begin{array}{l}2.905 \\
0.000\end{array}$}} \\
\hline Sig & \multicolumn{3}{|c|}{0.000} & & & 0.000 \\
\hline
\end{tabular}

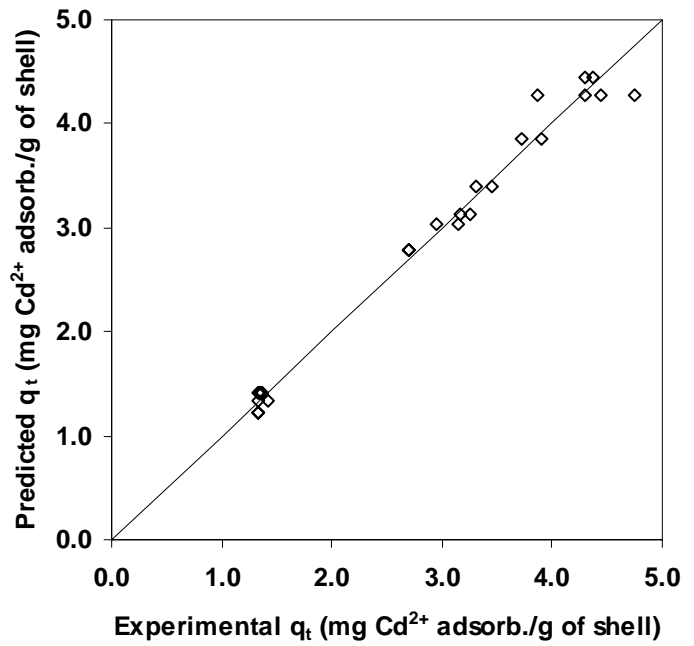

Figure 1. Predicted vs. experimental values for sorption capacity of chestnut shell for the removal of cadmium ions 

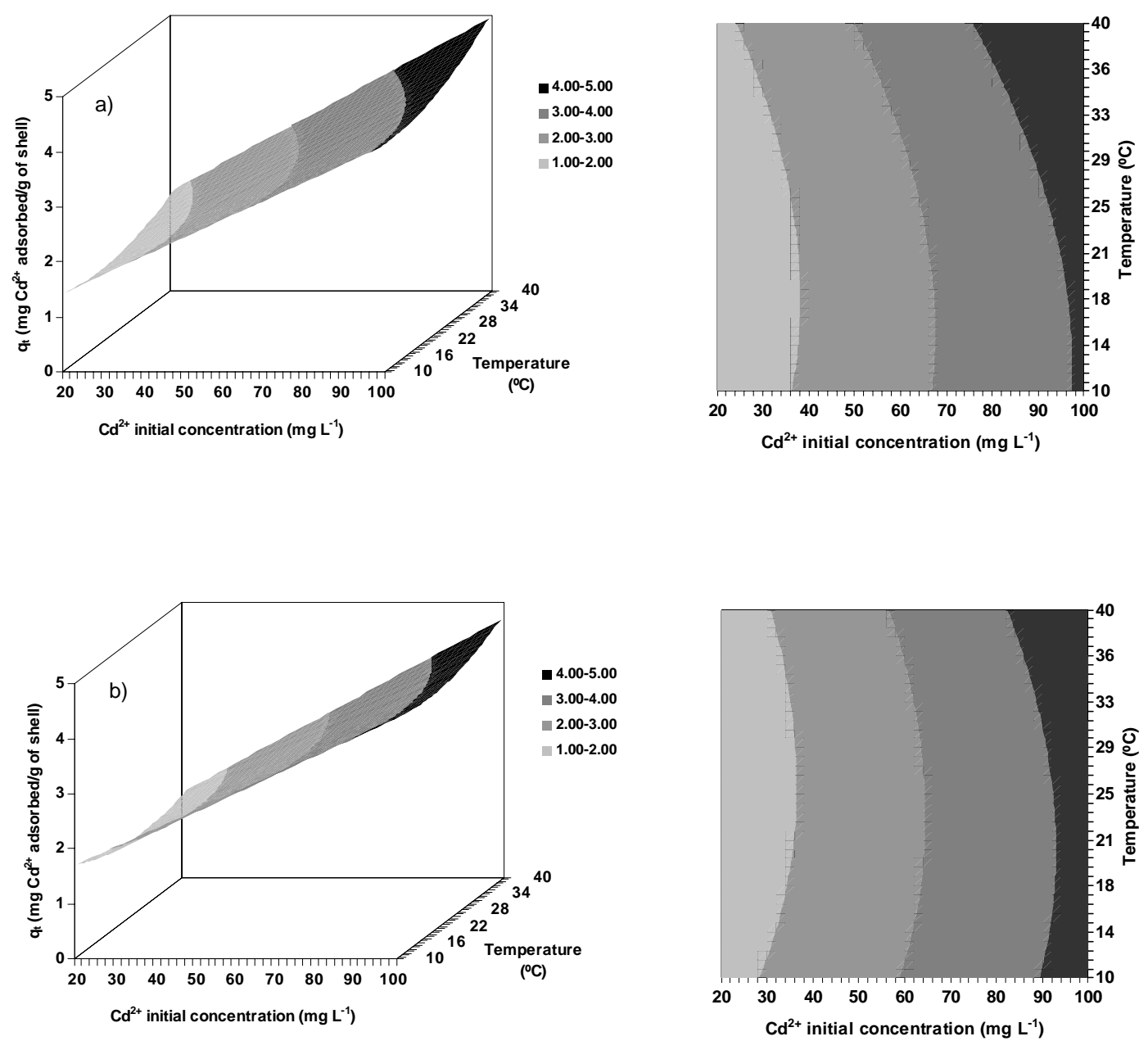

Figure 2. Dependence of cadmium adsorption capacity $\left(\mathrm{Y}_{1}\right)$ of chestnut shell on initial concentration $\left(\mathrm{X}_{1}\right)$ and temperature $\left(\mathrm{X}_{2}\right)$ for a) $\mathrm{pH}=5.5$ and b) $\mathrm{pH}=8.5$

The analysis of the results obtained has suggested that the optimum adsorption conditions were the natural $\mathrm{pH}$ of the solutions (around 5.5) for both contaminants and $25^{\circ} \mathrm{C}$ for cadmium adsorption and $60^{\circ} \mathrm{C}$ for phenol adsorption. Therefore, the adsorption equilibrium experiments were performed in these conditions.

The equilibrium distribution of cadmium ions and phenol between the chestnut shell and the solution is important to determine the maximum sorption capacity of the shell for cadmium ions or phenol and to understand the mechanism of adsorption. To assess the Langmuir and Freundlich isotherms and their ability to correlate the experimental results, the linearised plots for each isotherm have been performed in the forms of Eq. 2 and 3, respectively:

$$
\frac{C_{e}}{q_{e}}=\frac{1}{K_{L} \cdot q_{m}}+\frac{C_{e}}{q_{m}}
$$

$q_{m}$ is the amount of $\mathrm{Cd}^{2+}$ or phenol adsorbed per unit mass of the chestnut shell in a single monolayer, $K_{L}$ is a parameter related to the energy of adsorption $\left(K_{L}=k_{a} / k_{d}, k_{a}\right.$ and $k_{d}$ are the adsorption and desorption rate constants for the adsorption equilibrium, respectively,) and $\mathrm{C}_{e}$ and $\mathrm{q}_{\mathrm{e}}$ are the equilibrium liquid phase and solid phase concentrations, respectively, of $\mathrm{Cd}^{2+}$ or phenol.

$\ln q_{e}=\ln K_{F}+\frac{1}{n} \ln C_{e}$ 

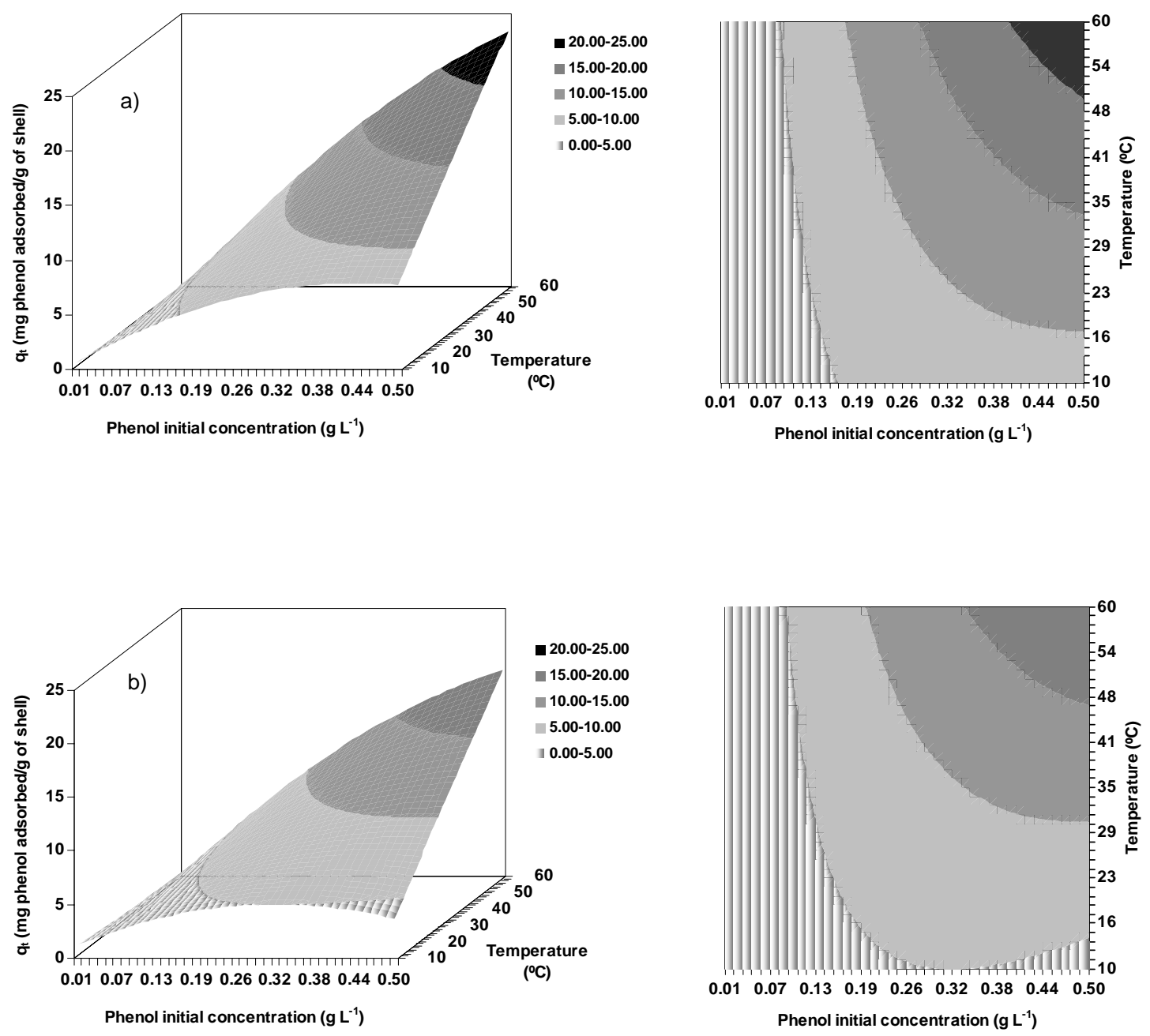

Figure 3. Dependence of phenol adsorption capacity $\left(\mathrm{Y}_{1}\right)$ of chestnut shell on initial concentration $\left(\mathrm{X}_{1}\right)$ and temperature $\left(\mathrm{X}_{2}\right)$ for a) $\mathrm{pH}=2.5$ and b) $\mathrm{pH}=9.5$

$\mathrm{K}_{\mathrm{F}}$ and $1 / \mathrm{n}$ are the Freundlich constants indicating the relative adsorption capacity and the intensity of adsorption, respectively.

For cadmium ions adsorption equilibrium, it was found that the correlation coefficient was higher than $0.97(p<0.01)$ for the Freundlich isotherm but unacceptable for the Langmuir model. Therefore, on the comparison of the $\mathrm{R}^{2}$ values, it could be concluded that Freundlich equation represented a better fit to the experimental data than the Langmuir equation. This result predicted the heterogeneity of the adsorption sites on chestnut shell for cadmium adsorption. Figure 4 shows the calculated Freundlich isotherm for cadmium adsorption together the experimental data. 


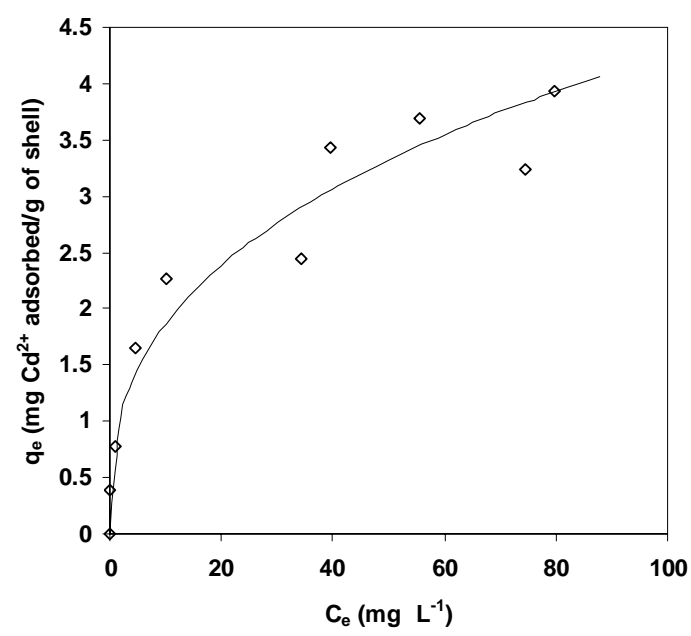

Figure 4. Freundlich isotherm for the adsorption of $\mathrm{Cd}^{2+}$ ions on chestnut shell at $\mathrm{pH}=5.5$ and $25^{\circ} \mathrm{C}$

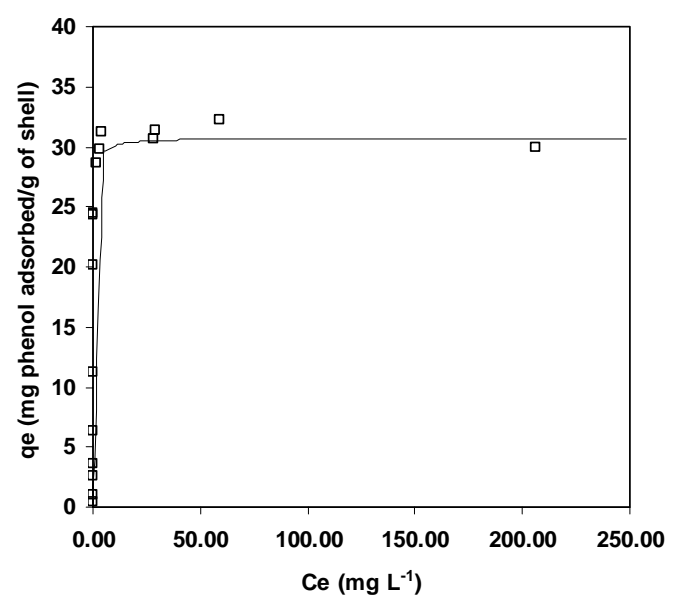

Figure 5. Langmuir isotherm for the adsorption of phenol on chestnut shell at $\mathrm{pH}$ $=5.5$ and $60^{\circ} \mathrm{C}$

The values of the Freundlich parameters, $\mathrm{K}_{F}, 0.812 \mathrm{mg}^{1-1 / n} \mathrm{~g}^{-1} \mathrm{I}^{1 / \mathrm{n}}$, and $\mathrm{n}, 2.78$, were comparable with the values obtained for other adsorbents (Ho and Ofojama, 2006; Meena et al., 2008; Garg et al., 2008b). Moreover, since $\mathrm{n}$ ranged from 1 to 10 it could be concluded that cadmium ions were favourably adsorbed by chestnut shell (Passos et al., 2006).

For phenol adsorption equilibrium, the Langmuir equation, with a correlation coefficient higher than $0.99(p<0.0001)$, represented a better fit to the experimental data than the Freundlich equation. Figure 5 shows calculated Langmuir isotherm for phenol adsorption together the experimental data. The parameters of the Langmuir model $\mathrm{K}_{\mathrm{L}}$ and $\mathrm{q}_{\mathrm{m}}$ took the values of $4648.9 \mathrm{~g}^{-1}$ and $0.0307 \mathrm{~g}$ of phenol/g of shell, respectively. The essential characteristics of the Langmuir isotherm can be expressed in terms of a dimensionless separation factor or equilibrium parameter $R_{\mathrm{L}}$ given by Eq. 4 :

$R_{L}=\frac{1}{1+K_{L} C_{0}}$

where $C_{0}$ is the highest initial phenol concentration essayed. The $R_{L}$ value, $2.68 \cdot 10^{-4}$, in the range from 0 to 1 indicated that the phenol adsorption by chestnut shell was favourable ( $\mathrm{Ho}$, 2003; Ghodbane et al., 2008; Meena et al., 2008).

\section{CONCLUSIONS}

The use of a factorial experimental design has allowed the identification of the most important factors influencing the cadmium ions and phenol adsorption employing chestnut shell as adsorbent.

The maximum amount of $\mathrm{Cd}^{2+}$ and phenol taken up by chestnut shell was 4.75 and 21.87 $\mathrm{mg} / \mathrm{g}$ of shell, respectively, in the operational conditions essayed.

According to the statistical analysis, initial concentration and temperature, in this order, were the most significant factors on both adsorption processes, being the $\mathrm{pH}$ the less significant factor in the ranges investigated.

The optimum adsorption conditions selected were the natural $\mathrm{pH}$ (around 5.5) for both $\mathrm{Cd}^{2+}$ ions and phenol, and a temperature of $25^{\circ} \mathrm{C}$ for $\mathrm{Cd}^{+2}$ and $60^{\circ} \mathrm{C}$ for phenol. The adsorption equilibrium data obtained under the optimised conditions were modelled by the Freundlich and the Langmuir isotherms for cadmium ions and phenol, respectively.

\section{ACKNOWLEDGEMENTS}

The authors are grateful to Ministerio de Educación y Ciencia, Plan Nacional de I+D+i (AGL200500273) and Xunta de Galicia (PGIDIT06PXIC265046PN) for the financial support of this work. 


\section{REFERENCES}

Aksu Z., (2001), Equilibrium and kinetic modelling of cadmium(II) biosorption by C. vulgaris in a batch system: effect of temperature, Sep. Purif. Technol., 21, 285-294.

Al-Anber Z.A. and Matouq M.A.D., (2008), Batch adsorption of cadmium ions from aqueous solution by means of olive cake, J. Hazard. Mater., 151, 194-201.

Bailey S.E., Olin T.J., Bricka R.M. and Adrian D.D., (1999), A review of potentially low-cost sorbents for heavy metals, Water Res., 33(11), 2469-2479.

Calace N., Nardi E., Petronio B.M. and Pietroletti M., (2002), Adsorption of phenols by papermill sludges, Environ. Pollut., 118, 315-319.

Carmona M.E.R., Pereira M.A. and Ferreira S.G., (2005), Biosorption of chromium using factorial experimental design, Process Biochem., 40, 779-788.

Dursun G., Çiçek H. and Dursun A.Y., (2005), Adsorption of phenol from aqueous solution by using carbonised beet pulp, J. Hazard. Mater., B125, 175-182.

Fiset J.F., Blais J.F., Cheikh R.B. and Tyagi R.D. ,(2000), Revue sur l'enlèvement des mètaux des effluents par adsorption sur la sciure et les écorces de bois, Rev. Sci. Eau, 13(3), 325-349.

Garg U.K., Kaur M.P., Garg V.K. and Sud D., (2008a), Removal of nickel(II) from aqueous solution by adsorption on agricultural waste biomass using a response surface methodological approach, Bioresource Technol., 99, 1325-1331.

Garg U.K., Kaur M.P., Jawa G. K., Sud D. and Garg V.K., (2008b), Removal of cadmium(II) from aqueous solution by adsorption on agricultural waste biomass, J. Hazard. Mater., 154, 11491157.

Ghodbane I., Nouri L., Hamdaoui O. and Chiha M., (2008), Kinetic and equilibrium study for the sorption of cadmium (II) ions from aqueous phase by eucalyptus bark, J. Hazard. Mater., 152, 148-158.

Goud V.V., Mohanty K., Rao M.S. and Jayakumar N.S., (2005), Phenol removal from aqueous solutions by tamarind nutshell activated carbon: batch and column studies, Chem. Eng. Technol., 28(7), 814-821.

Ho Y. and McKay G., (1999), Pseudo-second order model for sorption processes, Process Biochem., 34, 451-463.

Ho, Y. (2003), Removal of copper ions from aqueous solutions by tree fern, Water Res., 37(10), 2323-2330.

Ho Y. and. Ofojama A.E., (2006), Biosorption thermodynamics of cadmium on coconut copra meal as biosorbent, Biochem. Eng. J., 30(2), 117-123.

Huang W., Zhenshan L., Niu H., Li D. and Zhang J., (2008), Optimization of operating parameters for supercritical carbon dioxide extraction of lycopene by response surface methodology, $\mathrm{J}$. Food Eng., 89, 298-302.

Krishnani K., Meng X., Christodoulatos C. and Boddu V.M., (2008), Biosorption mechanism of nine different heavy metals onto biomatrix from rice husk, J. Hazard. Mater., 153, 1222-1234.

Meena A.K., Kadirvelu K., Mishraa G.K., Rajagopal Ch. and Nagar P.N., (2008), Adsorption of $\mathrm{Pb}(\mathrm{II})$ and $\mathrm{Cd}(\mathrm{II})$ metal ions from aqueous solutions by mustard husk, J. Hazard. Mater., 150, 619-625.

Passos C.G., Ribaski F.S., Simon N.M., dos Santos A.A., Vaghetti J.C.P., Benvenutti E.V. and Lima E.C., (2006), Use of statistical design of experiments to evaluate the sorption capacity of 7-amine-4-azaheptylsilica and 10-amine-azadecylsilica for $\mathrm{Cu}(\mathrm{II}), \mathrm{Pb}(\mathrm{II})$, and $\mathrm{Fe}(\mathrm{III})$ adsorption, J. Colloid Interface Sci., 302, 396-407.

Rao J.R. and Viraraghavan T., (2002), Biosorption of phenol from an aqueous solution by Aspergillus niger biomass, Bioresource Technol., 85, 165-171.

Vázquez G., Antorrena G., González J. and Doval M.D., (1994), Adsorption of heavy metal ions by chemically modified Pinus pinaster bark, Bioresource Technol., 48, 251-255.

Vázquez G., González-Álvarez J., García A.I., Freire M.S. and Antorrena G., (2007), Adsorption of phenol on formaldehyde-pretreated Pinus pinaster bark: Equilibrium and kinetics. Bioresource Technol., 98, 1535-1540.

Vázquez, G., Fontenla E., Santos J., Freire M.S., González-Álvarez J. and Antorrena G., (2008), Antioxidant activity and phenolic content of chestnut (Castanea sativa) shell and eucalyptus (Eucalyptus globulus) bark extracts, Ind. Crops Prod., 28, 279-285. 